worldwide? Either way his pronouncement is nonsense I am personally acquainted with psychiatrists in academe in Toronto who are very much involved with and practise psychoanalysis. Also, I live in Italy, where psychoanalysis is alive and well as ever.

Harold Bourne FRCPsych, Rome, Italy, email: bourneharold@hotmail.com doi: $10.1192 / \mathrm{pb} .35 .8 .314 \mathrm{~b}$

\section{Whistling in the wind}

There are reasons to be critical of Thomas Szasz's views about mental illness. For example, few would want to go as far as him in recommending that society manage without a mental health act. His definition of illness as physical lesion also unnecessarily excludes psychological dysfunction as illness.

In his commentary, Edward Shorter focuses on criticising Szasz on an issue on which he is in fact correct, namely that no biological markers have been found for mental illness. Shorter seems to be using his skills as a historian to suggest that psychiatry has overlooked what he calls obvious evidence of organicity from past research in the role of panicogens in triggering panic disorder; the response of catatonia to barbiturates and benzodiazepines; and hypothalamic-pituitary-adrenal dysregulation in melancholic depression (see my Critical Psychiatry blog entry on 16 May, http://criticalpsychiatry.blogspot.com). The general conclusion from this research, unlike that of Shorter, is that no biological cause of mental illness has been found. Even the American Psychiatric Association admit that 'brain science has not advanced to the point where scientists or clinicians can point to readily discernible pathologic lesions or genetic abnormalities that in and of themselves serve as reliable or predictive biomarkers of a given mental disorder or mental disorders as a group'.

Szasz has been dismissed as an anti-psychiatrist. Even 50 years later, the point of his 'myth of mental illness' has not been understood. Shorter's unscientific attack on Szasz does not promote the interests of psychiatry.

1 Shorter E. Still tilting at windmills: Commentary on ... The myth of mental illness. Psychiatrist 2011; 35: 183-4.

2 American Psychiatric Association. American Psychiatric Association Statement on Diagnosis and Treatment of Mental Disorders. Release no 03-39, September 25, 2003 (http://www.psych.org/MainMenu/ Newsroom/NewsReleases/2003NewsReleases/ mentaldisorders0339.aspx).

Duncan B. Double is consultant psychiatrist, Norfolk and Waveney Mental Health NHS Foundation Trust, Victoria House, Lowestoft NR32 1PL, UK, email: dbdouble@dbdouble.co.uk

doi: $10.1192 / \mathrm{pb} .35 .8 .315$

\section{Battling the wrong enemy!}

Dr Shorter's ad hominem attack on Professor Szasz provides no convincing argument against Szasz's well-known position concerning what he regards as the spurious medicalisation of mental illness. Nor will there be wide agreement with Shorter that neuroscientific studies suggesting a 'neurological basis for much psychiatric illness' negate Szasz's firmly held beliefs.

It is regrettable that Dr Shorter missed the opportunity to remind our colleagues that the rampant misuse of psychiatry
50 years ago as described by Szasz is applicable to the way institutional psychiatry is practised today in many parts of the USA, Canada and the UK, and certainly in most of the other countries in the world.

Abraham L. Halpern, MD, FRCPsych, FACPsych, Professor Emeritus of Psychiatry, New York Medical College, Valhalla, NY 10595, USA, email: ahalpern1@verizon.net

doi: 10.1192/pb.35.8.315a

\section{Another view of mental health tribunals}

Dr Choong writes of his perception that the number of Mental Health Act Section 2 detentions is rising, and refers to 'an uncritical approach to using guidance that results in Section 2 being used much more frequently now' and the 'waste of time and resources in dealing with the inevitable extra tribunals'.

His perception mirrors the national picture. From 1998/9 to $2008 / 9$, total uses of Section 2 in National Health Service (NHS) hospitals in England went from 20874 to $23482^{2}$ and the numbers continue to rise (25622 in 2009/10). ${ }^{3}$ Total use of Section 3 dropped slightly for the period 1998/9 to $2008 / 9,{ }^{2}$ from 22738 to 21538 . There was a corresponding increase in conversions from Section 2 to Section 3 (4048 to 5145). ${ }^{2}$ Data have to be examined carefully as figures may be given for England alone or England and Wales, give NHS and independent hospital figures either separately or together, and refer to total uses or admissions. Data usually refer to instances of detention, not the number of different individuals detained.

As to mental health tribunals being a waste of time and resources, I think there is room for another view. In 2007/ 2008, 21849 applications were received, of which 10380 were withdrawn before the hearing and 9137 were heard (3157 outstanding at year end); of those that were heard, $17 \%$ resulted in the section being discharged, which means over 1550 patients. ${ }^{4}$ It is not possible to say in how many cases the responsible clinician discharged the section in advance of the hearing because the impending hearing focused his or her attention on the question of whether continued detention was justifiable, but if this was the case in even $10 \%$ of those cases, this would amount to over 1000 patients being released from detention of doubtful legality because of a forthcoming tribunal.

If patients are first placed on Section 2 and then converted to Section 3, they will be entitled to two tribunal hearings within the first few months of detention, rather than the one they would have if Section 3 were used initially. Moreover, the first tribunal would occur within weeks of admission, instead of up to several months later. Given the substantial number of detentions that are ended by tribunals, the decision to use Section 3 rather than Section 2 initially would appear to result in a large number of people being detained on doubtful grounds for longer than necessary.

Statistics on mangers' panels are not published, so it is much more difficult to make a comparable argument about their usefulness based on objective information about their decisions.

As a clinician, I believe that the discipline of having to prepare for mental health tribunals by thinking through the reasons why my patients should be detained often leads to 
better decision-making and less restrictive care plans. The time it takes to write reports and attend tribunals seems a fair price to pay to ensure that those detained against their will have an effective right to challenge their situation.

1 Choong LS. The rise in the number of Section 2 detentions (letter). Psychiatrist 2011; 35: 198.

2 The NHS Information Centre. In-Patients Formally Detained in Hospitals under the Mental Health Act, 1983 and Patients Subject to Supervised Community Treatment: 1998-99 to 2008-09 (Appendix 2, Table 8). Health and Social Care Information Centre, 2009.

3 The NHS Information Centre, Community and Mental Health Team. InPatients Formally Detained in Hospitals under the Mental Health Act 1983 and Patients Subject to Supervised Community Treatment, Annual Figures, England 2009/10. Health and Social Care Information Centre, 2010 (http://www.ic.nhs.uk/pubs/inpatientdetmha0910).

4 Administrative Justice and Tribunals Council. Annual Report 2007/2008. TSO (The Stationery Office), 2008 (http://www.justice.gov.uk/ajtc/ docs/Annual_Report_2007_8.pdf).

Hugh Series is consultant psychiatrist and medical member of a first-tier mental health tribunal, Oxford Health NHS Foundation Trust and University of Oxford, UK, email: hugh.series@oxfordhealth.nhs.uk

doi: $10.1192 / \mathrm{pb} .35 .8 .315 b$

\section{Reader feedback is helpful, but are the leaflets readable?}

I was heartened to see an article evaluating the Royal College of Psychiatrists' patient information leaflets using quantitative and qualitative methods. ${ }^{1}$ The provision of information is critical to my clinical practice and has often involved these very leaflets. I was also pleased that the authors acknowledged that 'much patient information is written in complex language and is poorly presented' as these are often barriers to patients accessing information. Disappointingly, however, they did not conduct any analysis of the language; one respondent had commented regarding one leaflet that 'It has quite a high reading age'.

The complexity of language can be assessed using a range of readability measures such as Flesch Reading Ease (FRE; a document should have a score of greater than 60 , the higher the score the easier it is to read) and Flesch-Kincaid Grade Level (FKGL; refers to US school grades, so lower scores indicate better readability - a 13 year old should understand a document scoring 7). These are widely available, contained within word processing packages, and have been used to evaluate patient information leaflets in other specialties ${ }^{1}$ and standard appointment letters in child and adolescent mental health services. ${ }^{2}$ When these measures are applied to the College leaflets (Table 3 in the paper), the mean FRE is 7.81 (7.1-8.4) and mean FKGL 63.13 (58.7-69.8). This suggests the leaflets are readable as far as these computerised measures are concerned but their readability could be improved. When the top- and bottom-ranked leaflets (Table 3, which, curiously, has four highest ranked and three lowest ranked rather than four of each as described in the text) are compared, there is no statistical difference on either of the measures. This confirms that, although the language may be readable, the reader may not like the content.

I was confused by the quantitative method employed in the study. The original feedback was on a 5-point Likert scale ranging from 'strongly agree' to 'strongly disagree'. These are ordinal variables (variables which represent categories of a feature with some inherent ordering ${ }^{3}$ ); however, they were converted into continuous variables (one which can take any value within a range ${ }^{3}$ ) and analysed as such. Unfortunately, one cannot convert discrete categories into a linear scale in this way. Given this conversion, the values could only range $1-5$, and it is unsurprising that the authors found there was little variability in the feedback 'scores' assigned to each leaflet. It was also confusing to find that a correlation between modalities was included in the discussion but not presented in the results. My understanding of the analysis would have been aided to see the information presented in the original categories which those reading the leaflets had decided.

Despite these potential improvements and confusions, the conclusion remains undoubtedly true that 'reader feedback provides invaluable guidance about the substance and presentation of our public mental health information.' One can only hope that we continue to strive to produce information which is accessible to those who need it.

1 Briscoe M, Briscoe S, Timms P, Ramsay R. Usefulness of reader feedback on the Royal College of Psychiatrists' public information leaflets. Psychiatrist 2011; 35: 175-8.

2 Payne S, Large S, Jarrett N, Turner P. Written information given to patients and families by palliative care units: a national survey. Lancet 2000; 355: 1792.

3 Bennett DM, Gilchrist A. Readability of standard appointment letters. J Ment Health Fam Med 2010; 7: 101-6.

4 Harris M, Taylor G. Medical Statistics Made Easy (2nd edn). Scion, 2009.

Daniel M. Bennett, clinical lecturer in psychiatry and honorary specialty registrar in forensic psychiatry, University of Aberdeen, UK, email: danielm.bennett@nhs.net

doi: $10.1192 / p b .35 .8 .316$

\section{Readability analysis?}

As a trainee member of the Royal College of Psychiatrists' Public Education Editorial Board, I read with interest the review of reader feedback on the College online public education leaflets. ${ }^{1}$ I was struck by both the popularity of the public information section of the website and the high volume of completed feedback forms. I wondered, however, whether the authors have considered further analysis of the College information leaflets, to identify potential causes for the poorly scoring leaflets that they describe in the article.

The authors refer to an analysis of free-text feedback in which they name the two highest and lowest scoring main leaflets. It is perhaps unsurprising that poorly scoring leaflets would be more likely to receive negative comments, but what interested me most was the example constructive comment in response to the cannabis and mental health leaflet that said 'It has quite a high reading age'.

If the College information leaflets aim to reach a wide audience, it would seem sensible to establish whether the comment about reading age is in fact true for all leaflets. Is their readability consistent with the recommended level? And have the authors considered analysing whether there is a correlation between the reading age of the highest and lowest scoring leaflets? 